\title{
Quilombos e Educação: identidades em disputa
}

\section{Quilombos and Education: identities in dispute}

\author{
Shirley Aparecida de Miranda*
}

\begin{abstract}
RESUMO
Este artigo apresenta uma análise da categoria quilombo em suas interfaces com a educação a partir de dados da pesquisa nacional intitulada "Educação e Relações Étnico-Raciais: estado da arte" considerando as dissertações e teses mapeados no período de 2003 a 2014 sobre a temática. Nesse artigo discutimos, a partir das pesquisas analisadas, os dilemas da constituição das identidades quilombolas em interface com a educação escolar. Identificou-se como tendência predominante nas pesquisas a utilização de uma noção de quilombos derivada do reconhecimento jurídico das comunidades remanescentes de quilombo. Verificou-se a adoção de uma concepção de identidade quilombola construída em meio a lógicas de funcionamento do racismo e aos dilemas do pertencimento a um determinado território material e simbólico inserido em disputas econômicas. Constatou-se que a educação escolar quilombola, a tendência predominante é confrontação entre a educação quilombola e aquela que ocorre na escola que, no formato atual, obstaculiza ou pouco colabora na construção de uma identidade afrodescendente. A educação escolar quilombola diferenciada permanece em disputa.

Palavras-chave: Quilombo. Identidade. Educação.
\end{abstract}

\begin{abstract}
This article presents an analysis of the quilombo category in its interfaces with education based on data from the national research entitled "Education and Ethnic-Racial Relations: state of the art" considering the dissertations and theses mapped in the period from 2003 to 2014 on the subject. In this article, we discuss the dilemmas of the constitution of the quilombola identities rais. Brasil. E-mail: mirandashirley48@gmail.com._ORCID: https://orcid.org/0000-0001-8312-2262
\end{abstract}


in interface with the school education. It was identified as a predominant tendency in the researches the use of a notion of quilombos derived from the juridical recognition of the remaining quilombo communities. It was verified the adoption of a conception of quilombola identity built in the middle of the logics of the functioning of racism and the dilemmas of belonging to a certain material and symbolic territory inserted in economic disputes. It was found that quilombola school education, the predominant tendency is a confrontation between quilombola education and that occurring in the school that, in the current format, hinders or little collaboration in the construction of an Afrodescendant identity. Differentiated quilombola school education remains in dispute.

Keywords: Quilombo. Identity. Education.

\section{Introdução}

Os quilombos no Brasil constituem um fenômeno histórico e político que atravessa a construção da nação brasileira e diz respeito à diáspora africana, ao racismo no Brasil, aos processos de resistência negra, bem como a cosmologias e territorialidades que compõem especificidades afrobrasileiras. Contemporaneamente, a educação passou a integrar as análises relativas aos quilombos, sobretudo a partir das Diretrizes Curriculares Nacionais para a Educação Escolar Quilombola na Educação Básica ${ }^{1}$.

Este artigo aborda o fenômeno dos quilombos com base em pesquisas que originaram dissertações e teses em programas de pós-graduação no período de 2003 a 2014. Nas nove teses e quarenta dissertações mapeadas dedicamo-nos a compreender as tendências da produção, identificando e interpretando as dimensões que entram em jogo nessas investigações. A distribuição dessa produção acadêmica demonstra as repercussões dos debates políticos em torno da configuração da educação escolar quilombola, a começar pela Conferência Nacional de Educação ocorrida em 2010, seguida pelo $1^{\circ}$ Seminário Nacional de Educação Quilombola, organizado pelo Ministério da Educação com a decisiva participação da Confederação Nacional de Articulação das Comunidades Quilombolas (CONAQ), no mesmo ano. Conforme observamos, a produção acadêmica sobre o tema educação e quilombos intensificou-se a partir de 2007, saltando de uma pesquisa concluída em 2006, para cinco em 2007. O ápice foi registrado em 2011, com a conclusão de 11 (onze) pesquisas.

1 Resolução CNE/CEB No 08/2012 (Brasil, 2012b). 
As pesquisas mapeadas referiram-se a cinquenta e uma comunidades quilombolas, sendo doze delas localizadas no estado da Bahia, seguido pelo estado de São Paulo onde foram registradas oito comunidades pesquisadas, com predominância para o Vale da Ribeira. Acentuamos que o estado da Bahia registra o maior índice de comunidades remanescentes de quilombos certificadas pela Fundação Cultural Palmares até $2016^{2}$, um total de quinhentas e noventa e sete comunidades. São Paulo registra cinquenta comunidades certificadas no mesmo período, o que consiste no oitavo lugar em número de comunidades quilombolas certificadas. Além do estado da Bahia, estados como Maranhão, Minas Gerais, Pará, Pernambuco, Rio Grande do Norte, Piauí e Alagoas superam os registros de São Paulo. Esses dados evidenciam que a visibilidade das comunidades remanescentes de quilombos nas pesquisas ainda permanece a depender da abertura dos programas de pós-graduação ao tema.

Por outro lado, observamos que as/os autoras/es das pesquisas optaram por não fazer uso de nomeação fictícia para as comunidades remanescentes de quilombos. Consideramos essa estratégia uma importante contribuição no sentido de conferir visibilidade aos quilombos, que ao longo da história do país sofreram variados processos de tentativas de destruição material e simbólica. Neste artigo discutimos, com base nas pesquisas analisadas, os dilemas da constituição das identidades quilombolas em interface com a educação escolar.

\section{Quilombos: significados em disputa}

Ao longo de mais de dois séculos, a conjugação de significados sobre os quilombos no Brasil e suas implicações na dinâmica política têm sido alvo de contestações. Entre a definição colonial relativa às habitações de escravos fugidos, geograficamente isoladas, situadas em uma natureza selvagem com padrões precários de moradia e produção exclusivamente agrícola para autoconsumo e àquela que foi construída no contexto das lutas por democratização do Estado, emergência de direitos e igualdade racial, um longo trajeto se delineia. A insurgência das comunidades negras contemporâneas, rurais e urbanas, que resistiram aos artifícios de apagamento material e simbólico a que foram submetidas demarca ângulos da produção acadêmica. Considerar ou não os

2 O quadro geral das certidões expedidas pela Fundação Cultural Palmares, por estados e regiões do país, de acordo com a Portaria 104 de 20/05/2016 pode ser conferido em http://www. palmares.gov.br/?page_id=37551 (consulta em 20/11/2016). 
embates políticos, jurídicos, sociais e territoriais que articulam o fenômeno dos quilombos constituem as tendências de pesquisa.

A tendência mais persistente nas teses e dissertações analisadas é de se ponderar os efeitos discursivos da ressemantização dos quilombos a partir das tensões do reconhecimento jurídico. A definição de quilombo contida no Decreto 4887/03 é recorrentemente citada, mas há o cuidado para não constranger as comunidades pesquisas ao conceito decretado. Nesse âmbito problematizam-se a identidade quilombola, consideram-se as lutas fundiárias e as disposições territoriais, o acesso às políticas públicas, seus impasses e consequências.

Nessa tendência contemporânea dos estudos sobre quilombo localizam-se, por exemplo, as considerações de Oliveira, H. L. (2012) sobre "grupo étnico que teve continuidade e se apresenta atualmente como remanescente de quilombos" (OLIVEIRA, H. L., 2012, p. 18). Na análise desse autor, a reinterpretação jurídica permite a atualização do termo a partir da mobilização de grupos sociais. Destaca-se a resistência na manutenção dos atuais territórios e na luta por anexar áreas originais, numa dinâmica que tem como alicerce a singularidade expressa "no modo próprio de vivência, na manutenção cotidiana, na prática do acolhimento, na interação com o meio ambiente e com outras etnias" (OLIVEIRA, H. L., 2012, p. 218). Santana (2005, p. 15) também assume o sentido de quilombo vinculado às lutas de resistência à escravidão na construção da identidade e de "ser homem livre". E Larchert (2013, p. 9) indica a construção do território específico quilombola como expressão de uma "epistemologia da resistência" que estaria no pertencimento à natureza e na recorrência a memória para ligar os mundos disjuntos.

As abordagens nessa perspectiva costumam enfocar com maior ênfase a história de constituição dos quilombos em particular. É o caso da elaboração de Santos, M. P. (2012), que discute a história da comunidade negra rural Alto Alegre (CE), de modo a fazer face ao problema identificado pela autora: o apagamento da presença negra no Ceará. Silva, E. A. (2011) também explicita procedimentos do mesmo tipo. Segundo a autora, até os anos de 1990, a comunidade quilombola de Ivaporunduva era conhecida como bairro rural, bairro negro ou de negros ribeirinhos. A incorporação da denominação comunidade remanescente de quilombo Ivaporunduva "demarcou o início de processos de empoderamento" (SILVA, E. A. 2011, p. 11), com emissão de títulos de posse de terras na região do Vale da Ribeira e o acesso a programas sociais do governo federal e também estadual.

Implicações do processo de certificação como comunidades quilombolas são evidenciadas por Silva, T. M. (2011), que declara a expansão da comunidade em termos censitários, construção de estrada, acesso a políticas públicas e expansão da escola, com ampliação dos anos de atendimento, do número de 
docentes e investimento na formação desses docentes. Oliveira, S. N. S (2006) pretendeu significar as comunidades Magal, Barro Vermelho e Sítio do Mato por meio delas mesmas. Desse modo, expôs a ressignificação da identidade mangazeira e as estratégias componentes de uma identidade quilombola:

\begin{abstract}
Nessa trajetória tornou-se importante observar como elementos, anteriormente desprezados, são valorizados e reincorporados à cultura do lugar como, por exemplo, a prática de religião afro-brasileira (o Saravá). Outro aspecto a se considerar é o fortalecimento político das práticas culturais das comunidades, tais como a Marujada e a Roda de São Gonçalo. (OLIVEIRA, S. N. S, 2006, p. 23).
\end{abstract}

Santos, A. C. C. (2008) focalizou o quilombo de Mucambo de Baixo (BA) valendo-se da permanência das expressões étnico-raciais e culturais em um contexto hostil à sua etnocultura. A dinâmica de preservação e ressignificação de valores e expressões são, segundo o autor, "instrumentais socioculturais que foram capazes de elaborar e lançar mão" e assim enfrentar os desafios da convivência exógena (SANTOS, A.C.C, 2008, p. 168). Para o autor revelou-se uma "cultura negociada" com a apropriação de importantes expressões, como o reisado ou o santo reis e o domínio da técnica do fabrico de instrumentos musicais que "facilitaram a dinâmica de pressão, negociação e conquista da instalação de importantes órgãos públicos nos seus domínios territoriais, como a igreja católica, a escola e o posto de saúde" (SANTOS, A.C.C., 2008, p. 169).

Padinha (2009) averiguou, na comunidade remanescente de quilombo Menino Jesus (PA), as narrativas que deflagraram significados de uma identidade comum. Segundo a autora, rompendo uma linha de silenciamento, por intermédio do reconhecimento jurídico, a comunidade pôde ser narrada por ela mesma e construiu um outro lugar de onde "narra aos filhos e netos, às gerações futuras, a história de origem dessa nova comunidade" (PADINHA, 2009, p. 121).

Como expressam as pesquisas, o conceito de quilombo elaborado a partir da identidade relacionada à cultura configura-se como "instrumento vigoroso no processo de reconhecimento da identidade negra brasileira", (VIDEIRA, 2010. p. 23). Quando a manutenção da cultura passa a ser compreendida como estratégia de resistência, "forma de pensamento e prática social" é irrestrita à folclorização de artefatos e expressões. (VIDEIRA, P. L., 2010, p. 253).

A compreensão das formas de resistência ao apagamento das comunidades permite aproximações a uma identidade desnaturalizada. Cada comunidade qui- 
lombola é única na forma como articula e negocia aspectos históricos, territoriais e culturais numa lógica de resistência à própria dissolução.

Em menor escala, persistem abordagens que incorrem numa naturalização dos quilombos, por não se deterem ou por desconsiderarem a multidimensionalidade do fenômeno no Brasil. Nesses casos, tomam-se as comunidades quilombolas como comunidades tradicionais ou comunidades tradicionais do campo, sem discutir o significado de tradição e nem mesmo a situação fundiária; ou referem-se a comunidades negras e, ao mesmo tempo, negligenciam-se os efeitos do racismo na análise das relações que constituem as comunidades pesquisadas. Identificar quilombolas como sujeitos à margem das políticas e dos processos educacionais, sem que essa situação seja discutida como efeito do racismo exemplifica o risco dessa abordagem, qual seja, a naturalização da condição subalterna dessas comunidades. Em algumas pesquisas, percebemos a referência genérica às comunidades negras, sem que aspectos da construção histórica da comunidade, ou relações específicas na produção de um território sejam considerados. Localizamos produções acadêmicas que recorrem ao passado escravo, e, sem a devida acuidade com o tema da escravidão no Brasil congelam a definição de quilombo e atam a comunidade a um passado que nunca termina. A formulação "descendentes de escravos" encontrada em algumas pesquisas é um exemplo da naturalização de uma condição histórica e política, como se a população negra africana tivesse nascido escravizada e destinasse essa condição às gerações futuras.

O deslocamento operado na definição de quilombo repercutiu numa identidade negociada, forjada no decorrer de processos de invisibilidade ativamente produzida e de visibilidade insurgente. Assim, a inauguração de quilombolas como viáveis sujeitos de direitos trouxe à tona um problema político e epistêmico: a partir de que referências se define essa identidade?

A premissa que orienta a maioria das produções é de que as identidades não são fixas. A referência preponderante para os/as autores/as são os trabalhos de Stuart Hall (2006a, 2006b), que sustenta a crítica a uma concepção essencialista de identidade e, ao reposicionar esse conceito, possibilita uma análise estratégica e contingente. Com base nessa referência é possível conceber a identidade quilombola em meio aos dilemas de pertencimento a um determinado território material e simbólico inserido em disputas econômicas e ainda considerar o âmbito das representações sociais sobre quilombos negociadas ou contestadas. Uma identidade nem sempre reconhecida e que, portanto, é conquistada, agenciada e certamente disputada, inclusive pelo aparato científico. 


\section{Identidade quilombola em confronto com a escola}

Da concepção prevalente de identidade quilombola decorrem problemas de pesquisa comuns às dissertações e teses: como os próprios quilombolas se referem à sua identidade? Como as novas gerações aprendem o que é ser quilombola? Como esses sujeitos negociam e afirmam o seu pertencimento identitário? É recorrente a indagação sobre "como se dava a aprendizagem dessa identidade, ou seja, como os moradores transmitiam-na e quais os procedimentos adotados nessa educação do "ser quilombola"' (SOUZA, M. L. A., 2009, p. 08). Esse autor situa um processo de construção da identidade quilombola mediado em diferentes espaços e tempos do quilombo, tais como reuniões familiares, conversas em alguma das ruas do território, nos encontros de comunidades quilombolas, reuniões de debates com técnicos administrativos. Assevera o autor que durante o prosseguimento dos trabalhos de titulação das terras "os moradores aprendiam entre si ou com 'os outros' o significado de ser quilombola e de morar num quilombo" (SOUZA, M. L. A., 2009, p. 170).

Outras/os autoras/es analisaram como se aprende e se ensina a ser quilombola, ou seja, como se transmitem conteúdos simbólicos comuns que sustentam "um desejo coletivo de resistir a um modo de vida excludente, aliado à garantia de sua própria sobrevivência" (SANTANA, 2005, p. 15). Nessa dinâmica identificam-se processos educativos que transmitem, de geração a geração, os significados que sustentam os laços da comunidade.

As investigações sobre a identidade quilombola deixam transparecer uma distinção entre a educação quilombola, que consiste na transmissão dos conteúdos simbólicos que ensinam o que é ser quilombola, e a educação escolar quilombola, que diz respeito aos processos desenvolvidos na instituição escolar.

No caso da educação escolar quilombola, as pesquisas dedicam-se a compreender como se constrói e se afirma a identidade étnica de crianças negras na inter-relação escola, família e comunidade. Sobre esse aspecto, Santos, A. C. C. (2008) constatou tratar-se de um processo conflituoso, no qual a escola pouco colabora. Segundo a autora, a ação pedagógica pouco reflexiva, o currículo eurocêntrico que desvaloriza a herança africana e a persistência da ideologia do branqueamento não concorrem para a afirmação da identidade da criança negra.

Na mesma direção, Leite (2009) constatou que as crianças se formam em meio a um diálogo intergeracional que ocorre na comunidade. Em contrapartida, a instituição escolar desconhece o contexto da comunidade quilombola e, desse modo, "diferenças tornam-se invisíveis e a escola não procede ao enfrentamento do preconceito" (LEITE, 2009, p. 158). 
Em outro prisma, Paula (2014) investigou as especificidades das crianças quilombolas imersas em dois contextos educativos: quilombo e educação infantil institucionalizada. A conclusão da autora caracteriza uma educação quilombola que ocorre nos meandros de práticas sociais cotidianas das quais as crianças são chamadas a participar, eventos comunitários que possibilitam que se inteirem "dos acontecimentos, dos modos de agir e de pensar do grupo, enfim, para que possam dar continuidade ao trabalho desenvolvido, preservando a tradição" (PAULA, 2014, p. 285). Segundo a autora, os laços parentais e de cumplicidade possibilitam instituir uma ordem diferente da convencional, com referências de estilos e de estética, formas de pensar, de agir e de brincar que caracterizam "uma cultura infantil quilombola [...] como base e ancoragem para sua circulação em outros espaços institucionais" (PAULA, 2014, p. 285). Desse modo,

Os limites impostos a essas crianças e os constrangimentos pelos quais passam na escola são superados por elas, na maioria das vezes sem a intervenção ou mesmo ciência dos adultos, tendo como base para suas ações e reações frente às sujeições, em especial enunciadas por outras crianças, seu grupo de pertença identitária. É essa constituição de grupo que dá o indicativo de sua alteridade frente a outros grupos, o que lhes possibilita a construção de um lugar social e de manifestação de uma cultura infantil quilombola, ainda que à revelia do olhar dos adultos. (PAULA, 2014, p. 289).

Outro conjunto de pesquisas com o enfoque na relação entre a identidade quilombola e a escola indaga como a história e a cultura dos jovens, bem como suas vivências e interpretações de mundo são contempladas na escola que frequentam fora do quilombo. O problemático deslocamento dos jovens para escolas fora do quilombo com objetivo de continuidade de estudos é frequentemente tematizado. E, mais uma vez aponta-se o distanciamento entre a escola e as vivências, costumes e experiências de quilombolas, nesse caso, as/os jovens. Costa, L. M. L. (2012), por exemplo, contatou que a escola "não participa ou se envolve, por exemplo, nas festas tradicionais das comunidades do seu entorno" e desvaloriza a identidade daqueles jovens ao "inferiorizar a história, as lutas e conquistas, reproduzindo discursos e estereótipos que ocultam a diversidade da população afrodescendente" (COSTA, L. M., 2012 p. 245). A essa constatação também chegou Fernandes (2013), que observou os preconceitos e a discriminação a incidir sobre jovens quilombolas, na transição entre a escola do quilombo para a escola da cidade para a continuidade dos 
estudos. Em outra direção, Coelho (2013) verificou a distância entre os saberes escolares e os saberes da comunidade quilombola concluindo que os modos de vida, cultura e conhecimentos existentes nos quilombos, bem como sobre as lutas pela ressignificação desses territórios, são preocupações com que os jovens se ocupam e que não são tematizadas na prática pedagógica escolar. Já Silva, K. I. M. (2014) identifica a exclusão de jovens que ocorre com a negação de uma escola com a qual os quilombolas possam se identificar, o que conduz ao fracasso escolar. A segunda situação que os jovens enfrentam é que na escola da cidade são percebidos através do estereótipo da origem e experimentam "a diferença que os inferioriza" (SILVA, K. I. M., 2014, p. 131).

\section{Educação escolar quilombola: disputas na textura das comunidades}

Os tópicos anteriores prenunciaram os modos como a educação figura na lógica constitutiva das comunidades quilombolas, considerando-se predominantemente a produção das identidades e as disputas por reconhecimento. Essas lógicas desdobram-se na compreensão de uma diferença entre a educação quilombola, que ocorre nas práticas sociais cotidianas das comunidades, e uma educação escolar que se desenvolve dentro ou fora dos quilombos. Como assinalamos, a partir das Diretrizes Curriculares Nacionais para a Educação Escolar Quilombola na Educação Básica, a escola passou a integrar as práticas discursivas que, em âmbito jurídico, promovem o reconhecimento das comunidades remanescentes de quilombos instaurando o direito à preservação de suas formas especificas de viver e de pensar, de manter e utilizar culturas, seus modos próprios de produção, reelaboração e transmissão de conhecimento. Desse modo, a escola emergiu como problema de investigação pertinente.

Até 2009 preponderou a relação entre educação e identidade quilombola, com destaque para a cultura e as práticas sociais e para a memória na atualização da história dos quilombos. Quando a escola compareceu nas produções foi como obstáculo para afirmação da identidade, como evidencia Reis (2003). A autora asseverou o reduzido envolvimento do corpo docente da escola com o contexto da comunidade, comprovado nas "atividades desenvolvidas pelos professores ou mesmo pelo tratamento dado aos conteúdos" (REIS, 2003, p. 84). Outro âmbito de obstáculos colocados pela escola foi observado por Silva, C. R. (2008) no tratamento conferido pela escola à linguagem de estudantes de uma comunidade quilombola. Segundo a autora, "tonalidade da pele e a linguagem eram frequentemente tidas como alvo de discriminação" (SILVA, C. R., 2008, p. 17). 
Souza, M. L. A. (2009, p. 172), por sua vez, concluiu que as escolas não contribuem para a valorização da identidade quilombola dos estudantes porque negam a luta das comunidades "inferiorizando sua história ao apresentar o negro apenas na situação de subalterno e os quilombos de maneira enrijecida e focada na fuga e na perseguição". Por fim, Leite (2009, p. 156) assevera que quando a escola desconhece sua importância enquanto espaço político na dinâmica do reconhecimento da identidade quilombola corre o risco de "vendar os olhos às diferenças e tornar invisíveis aqueles que precisam dessa discussão e referência".

De 2010 em diante é que a escola passou a figurar como uma instância a ser disputada na consolidação de uma identidade quilombola, evidenciando-se seus limites, assim como suas potencialidades. Temas específicos das pesquisas em educação escolar despontaram, como currículo (FERREIRA, 2014), formação docente (SANTOS, G. K. C., 2011; PEDROZA, 2014) e implantação de políticas educacionais (CRUZ, 2012; SOARES, E. G, 2012).

A tônica central das investigações refere-se às tensões entre a escola e as comunidades quilombolas. Pavão (2010, p. 11) oferece uma síntese da compreensão que orienta a maioria dos/as autores/as no qual a escola como instituição escolar pública assume uma função "de dominação, de negação e/ou silenciamento do diverso", ao mesmo tempo em que é atravessada por confrontos de interesses:

de um lado, uma organização oficial do sistema escolar que define conteúdos e funções, organiza, separa, hierarquiza os espaços; de outro, os sujeitos, os/as educandos/as, professores/as e funcionários/as, que criam inter-relações fazendo da escola um processo de permanente construção sociocultural. (PAVÃO, 2010, p. 11).

Em outra perspectiva, identificamos trabalhos que tematizam as relações de proximidade entre a educação escolar quilombola e a educação quilombola, marcadamente nas práticas sociais cotidianas de produção e transmissão de conhecimentos nas escolas quilombolas, algumas em fase de sedimentação. Essa conclusão se encontra na pesquisa desenvolvida por Videira (2010), que analisou a cultura constituída e experienciada pela comunidade do Cria-Ú, em específico as danças do Batuque e do Marabaixo, como elementos que participam e ressignificam a práxis educativa e curricular que visa à valorização da história e cultura africana e afro-brasileira. Concluiu que as danças proporcionam articulação entre a prática educativa e o patrimônio cultural da comunidade. Oliveira (2006, p. 23) pesquisou a escola que atende a três comunidades quilombolas do estado da Bahia, à época recém-certificadas e observou o movimento que vai 
se consolidando em torno da instituição, "transformada em símbolo político e pedagógico para este novo momento da comunidade". Nesse caso registram-se formas de apropriação a partir do qual a escola passa a ser interpelada como quilombola:

mesmo não sendo nenhum modelo pedagógico revolucionário no sentido de romper com as práticas que secularmente se materializam na escola, esta pode ser considerada como uma escola do Quilombo posto que, após o reconhecimento eles se apropriam dela e começam a se preocupar com o que se aprende na escola e a se fazer presente na escola atentos à escolha de saberes que possam contribuir de fato na formação de sujeitos que sejam capazes de se relacionar com a cultura do outro sem permitir que sejam aculturados. Indivíduos que estejam abertos à troca, e rejeitam os saberes historicamente impostos. Além disso, a comunidade conquista um poder de decisão com relação às atividades escolares que outrora não existiam na Comunidade o que lhes possibilita maior poder de negociação junto ao poder público. (OLIVEIRA, 2006, p. 24).

Silva, E. A. (2011) verificou o processo de constituição de uma proposta de ensino implantada numa escola situada no Vale do Ribeira criada em 2004 a partir da demanda das seis comunidades quilombolas a que atende. A pesquisa investigou a participação do movimento quilombola no processo de criação da escola, as mudanças pedagógicas entre 2005 e 2010 e a relação da escola com valorização cultural e o fortalecimento da identidade quilombola. $\mathrm{O}$ autor chegou a um conceito de escola diferenciada: "uma concepção de educação que expande os espaços escolares alcançando e envolvendo a comunidade de forma ampla" (SILVA, E. A., p. 98).

Na mesma direção, Silva, M. A. M. $(2014,114)$ define a escola quilombola diferenciada como "uma escola que está sendo estruturada fisicamente e principalmente em seu currículo voltado para uma educação articulada entre o saber local e a educação escolar formal".

Silva, G. M. (2012, p. 165) define a educação escolar quilombola com base nas ações desenvolvidas no território quilombola de Conceição das Crioulas, em que "a escola é a referência ou o eixo que estrutura e conduz muitos desses processos". A autora ressalta que a função da escola daquela comunidade "é determinada pelo seu contexto e por aquilo que as representações da comunidade entendem ser, mesmo dentro de um campo de batalha e de concorrência" (SILVA, G. M., p. 166) e com base nessa percepção, define a "educação escolar quilombola diferenciada": 
A diferença reside em conseguir socializar os conhecimentos gerais já normatizados e convencionados nos sistemas de ensino e aqueles conhecimentos que a comunidade entende serem importantes, mas ainda não são vistos ou aprendidos por meio da escola. Educação Escolar Quilombola é um instrumento de luta, de identificação, de acolhimento dos conhecimentos locais e universais, de valorização da pessoa, da afirmação enquanto sujeitos de direitos, conforme mencionado. (SILVA, G. M., p.167).

O que demarca, então, educação escolar diferenciada? Um argumento categórico é a localização dessas escolas no território da comunidade, a fim de intensificar a participação das comunidades nas definições curriculares e a incorporação da cultura como saber. Alguns questionamentos não encontram fácil resolução. Por exemplo, como é possível estabelecer uma educação diferenciada, intercultural e democrática com uma visão eurocêntrica das origens do conhecimento científico? (SILVA, E. A., 2011, p. 15). A própria autora indica a erradicação de um modelo eurocêntrico de educação pelo reconhecimento e valorização das diferentes. Dias, A. O. (2012, p. 92) propõe a valorização estética, identidades e valores da cultura negra quilombola. Videira, P. L. (2010) sinaliza o respeito às tradições culturais e religiosas dos educandos e Silva, C. R. (2008) afirma a importância da presença de diversas "culturas linguísticas" na escola, a fim de desmitificar a natureza do "certo e errado". Essas são algumas das indicações contidas nas produções sobre o tema e evidenciam que a educação escolar quilombola é uma instância em disputa. Pesquisas sobre o agenciamento da educação escolar quilombola pelas comunidades, ou seja, a forma como a educação escolar é demandada, negociada, disputada por meio da força do reconhecimento jurídico alcançado pelos quilombos trarão importantes contribuições.

\section{REFERÊNCIAS}

BRASIL. Parecer CNE/CEB $N^{o}$ 16, de 20 de novembro de 2012. Brasília (DF), 2012a. BRASIL. Resolução CNE/CEB $N^{\circ} 8$, de 20 de novembro de 2012. Brasília (DF), 2012 b. CARVALHO, C. C. F. Ser no brincar, o brincar de ser o grupo: um estudo sobre a noção de pertença numa comunidade negra do Mutuca em Nossa Senhora do Livramento. 2008. Dissertação (Mestrado em Educação) - Universidade Federal de Mato Grosso, Cuiabá, 2008. 
CRUZ, C. M. Trajetórias, lugares e encruzilhadas na construção da política de Educação Escolar Quilombola no Paraná no início do III milênio. 2012. Dissertação (Mestrado em Educação) - Universidade Federal do Paraná, Curitiba, 2012.

COELHO, R. F. G. As educações escolar e social na formação da identidade racial de jovens nos quilombos de São João do Piauí. 2013. Dissertação (Mestrado em Educação) - Universidade Federal do Piauí, Teresina, 2013.

COSTA, L. M. L. Sou quilombola, bom aluno e bom de bola: a constituição identitária de alunos do ensino médio: um estudo histórico antropológico com jovens moradores de uma comunidade remanescente de quilombo do sertão mineiro, Minas Novas-MG. 2012. Dissertação (Mestrado em Educação) - Pontifícia Universidade Católica de Minas Gerais, Belo Horizonte, 2012.

FERNANDES, M. C. R. Mbaétaraca: uma experiência de educação de jovens quilombolas no município de Nilo Peçanha - BA. 2013. Dissertação (Mestrado em Educação e Contemporaneidade) - Universidade do Estado da Bahia, Salvador, 2013.

FERREIRA, A._O currículo em escolas quilombolas do Paraná: a possibilidade de um modo de ser, ver e dialogar com o mundo. 2014. Tese (Doutorado em Educação) - Pontifícia Universidade Católica de São Paulo, São Paulo, 2014.

HALL, S. A identidade cultural na pós-modernidade. Rio de Janeiro: DP\&A Editora, 2006a.

HALL, S. Da diáspora: identidades e mediações culturais. Belo Horizonte: Editora UFMG, 2006b.

LARCHERT, J. M. Resistência e seus processos educativos na comunidade negra rural quilombola do Fojo - BA. 2013. Tese (Doutorado em Educação) - Universidade Federal de São Carlos, São Carlos, 2013.

LEITE, G. M. C. Politicas públicas e olhares sobre a diferença: a criança quilombola na instituição escolar e em outros espaços educativos de Lagoa Trindade, Jequitibá, Minas Gerais. 2009. Dissertação (Mestrado em Educação) - Pontifícia Universidade Católica de Minas Gerais, Belo Horizonte, 2009.

OLIVEIRA, H. L. de. Comunidades remanescentes dos quilombolas de Arvinha e Mormaça: processos educativos na manutenção e recuperação do território. 2014. Tese (Doutorado em Educação) - Universidade do Vale do Rio dos Sinos, São Leopoldo, 2014.

OLIVEIRA, R. de C. M. de. Tessituras das diversidades: cultura(s) no cotidiano da escola de um território rural-quilombola. 2014. Dissertação (Mestrado em Educação e Contemporaneidade) - Universidade do Estado da Bahia, Salvador, 2014

OLIVEIRA, S. N. S. De mangazeiros a quilombolas: terra, educação e identidade em Mangal e Barro Vermelho Sítio do Mato - Bahia. 2006. Dissertação (Mestrado em Educação e Contemporaneidade) - Universidade do Estado da Bahia, Salvador, 2006. 
PADINHA, M. do S. R. Narrativas orais na Comunidade Remanescente de Quilombo Menino Jesus: processos de educação e memória. 2010. Dissertação (Mestrado em Educação) - Universidade do Estado do Pará, Belém, 2010.

PAULA, E. de. Entre o quilombo e a Educação Infantil: capturando expressões, experiências e conflitos de crianças quilombolas no entremeio desses contextos. 2014. Tese (Doutorado em Educação) - Universidade Federal de Santa Catarina, Florianópolis, 2014.

PAVÃO, M. C. Educação escolar e construção identitária na comunidade quilombola de Abacatal - PA. 2010. Dissertação (Mestrado em Educação) - Universidade do Estado do Pará, Belém, 2010.

REIS, M. C. G. Escola e contexto social: um estudo de processos de construção de identidade racial numa comunidade remanescente de quilombo. 2003. Dissertação (Mestrado em Educação) - Universidade Federal de Juiz de Fora, Juiz de Fora, 2003.

SANTANA, C. E. C. de. Processos educativos na formação de uma identidade em comunidades remanescentes de quilombos: um estudo sobre as comunidades de Barra / Bananal e Riacho das Pedras, no município de Rio de Contas - BA. 2005. Dissertação (Mestrado em Educação e Contemporaneidade) - Universidade do Estado da Bahia, Salvador, 2005.

SANTOS, A. C. C. Escola, família e comunidade quilombola na afirmação da identidade étnica da criança negra. 2008. Dissertação (Mestrado em Educação) - Universidade Federal de Alagoas, Maceió, 2008.

SANTOS, M. J. dos. Trajetória educacional de mulheres quilombolas no Quilombo das Onze Negras do Cabo de Santo Agostinho. 2012. Dissertação (Mestrado em Educação) - Pontifícia Universidade Católica de São Paulo, São Paulo, 2012.

SANTOS, M. P. dos. Incursão na história e memória da Comunidade de Quilombo de Alto Alegra município de Horizonte - CE. 2012. Dissertação (Mestrado em Educação) - Universidade Federal do Ceará, Fortaleza, 2012.

SILVA, C. P. da. Coco de roda novo quilombo: saberes da cultura popular e práticas de educação popular na comunidade quilombola de Ipiranga no Conde-PB. 2014. Dissertação (Mestrado em Educação) - Universidade Federal da Paraíba, João Pessoa, 2014.

SILVA, C. R. da. Vozes do silêncio: linguagem quilombola e preconceito linguístico-racial em Rio de Contas na Bahia. 2008. Dissertação (Mestrado em Educação e Contemporaneidade) - Universidade do Estado da Bahia, Salvador, 2008.

SILVA, E. A. da. A educação diferenciada para o fortalecimento da identidade quilombola: estudo nas comunidades remanescentes de quilombos do Vale do Ribeira. 2011. Dissertação (Mestrado em Educação: História, Política, Sociedade) - Pontifícia Universidade Católica de São Paulo, São Paulo, 2011.

SILVA, G. M. da. Educação como processo de luta política: a experiência de "educação diferenciada" do território quilombola de Conceição das Crioulas. 2012. Dissertação (Mestrado em Educação) - Universidade de Brasília, Brasília, 2012. 
SILVA, J. B. da. A educação formal afro-quilombola em Alagoas: limites e possibilidades de emancipação humana. 2012. Dissertação (Mestrado em Educação) - Universidade Federal de Alagoas, Maceió, 2012.

SILVA, K. I. M. A construção da identidade quilombola na percepção dos jovens de Araçá/Cariacá, Bom Jesus da Lapa - Bahia. 2014. Dissertação (Mestrado em Educação e Contemporaneidade) - Universidade do Estado da Bahia, Salvador, 2014.

SILVA, M. M. da. Educação escolar quilombola comunidades quilombolas do território quilombola de Vão Grande, Barra do Bugres - MT: percepções e significados sobre a E. E. José Mariano Bento. 2014. Dissertação (Mestrado em Educação) - Universidade do Estado do Mato Grosso, Cuiabá, 2014.

SILVA, T. M. da. A educação escolar na comunidade negra de Sibaúma: a trajetória educacional da Escola Municipal Armando de Paiva. 2011. Dissertação (Mestrado em Educação) - Universidade Federal do Rio Grande do Norte, Natal, 2011.

SOARES, E. G. Educação escolar quilombola: quando a política pública diferenciada é indiferente. 2012. Tese (Doutorado em Educação) - Universidade Federal do Paraná, Curitiba, 2012.

SOUZA, M. L. A. Educação e identidade no Quilombo Brotas. 2009. Dissertação (Mestrado em Educação) - Universidade Estadual de Campinas, Campinas, 2009.

VIDEIRA, P. L. Batuques, folias e ladainha: a cultura do quilombo Cria-Ú em Macapá e sua educação. 2010. Tese (Doutorado em Educação) - Universidade Federal do Ceará, Fortaleza, 2010.

Texto recebido em 30 de dezembro de 2017. Texto aprovado em 31 de dezembro de 2017. 
